\title{
Article \\ Research on the Method and Model for Calculating Impact Load in the Rockburst Tunnel
}

\author{
Zhiwei Yan ${ }^{1,2}$, Dagang Liu ${ }^{1, *}$, Zhilong Wang 1,2, Daming Zhao ${ }^{1,2}$ and Hongtao Tian ${ }^{1,2}$ \\ 1 School of Civil Engineering, Southwest Jiaotong University, Chengdu 610031, China; \\ 2019210073@my.swjtu.edu.cn (Z.Y.); zlwang@my.swjtu.edu.cn (Z.W.); daming_zhao@my.swjtu.edu.cn (D.Z.); \\ tianhingtao18@126.com (H.T.) \\ 2 Key Laboratory of Transportation Tunnel Engineering, Ministry of Education, Southwest Jiaotong University, \\ Chengdu 610031, China \\ * Correspondence: 1dg980272@163.com
}

check for

updates

Citation: Yan, Z.; Liu, D.; Wang, Z.;

Zhao, D.; Tian, H. Research on the Method and Model for Calculating Impact Load in the Rockburst Tunnel. Minerals 2022, 12, 13 .

https://doi.org/10.3390/ $\min 12010013$

Academic Editors: Diyuan Li, Zhenyu Han, Xin Cai, Shijie Xie and Abbas Taheri

Received: 27 October 2021 Accepted: 19 December 2021 Published: 22 December 2021

Publisher's Note: MDPI stays neutral with regard to jurisdictional claims in published maps and institutional affiliations.

Copyright: (c) 2021 by the authors Licensee MDPI, Basel, Switzerland. This article is an open access article distributed under the terms and conditions of the Creative Commons Attribution (CC BY) license (https:// creativecommons.org/licenses/by/ $4.0 /)$.

\begin{abstract}
Among several design methods of tunnel supporting structure, the load-structure method is widely used in different countries, but the determination of load is essential in this design method. The problem of rockburst is becoming more prominent as tunnel engineering enters the deep underground space. However, the research on the impact load on the supporting structure is insufficient in relevant fields. Therefore, from the perspective of energy, this paper deduces the method and model for calculating the impact load of the rockburst tunnel acting on the supporting structure by using the method of structural mechanics first, after the location effect of impact load is determined under different section types and different section sizes. The results indicated that: dynamic load factor $\mathrm{K}$ is related to the stiffness EI and supporting size coefficient $\mathrm{K}_{0}$ of the supporting structure, also the difference of impact load in different sections is proved. Tunnel rockburst-prone location is related to lateral pressure coefficient, thus when $\lambda=1$, the probability of rockburst in the whole circular tunnel is the same, while side wall and vault are prone to rockburst in single-track horseshoe tunnel, and the side wall is prone to rockburst in double-track horseshoe tunnel; furthermore when $\lambda>1$, the vault and the inverted arch are prone to rockburst; additionally, when $\lambda<1$, the rockburst is most likely to occur in the arch waist of the circular tunnel and the side walls and the arch waist of the horseshoe tunnel. Finally, the rockburst tunnel's local load-structure calculation model and the calculation process based on the model are provided.
\end{abstract}

Keywords: rockburst tunnel; impact load; calculation model; energy method

\section{Introduction}

Geotechnical engineering has long been concerned with deep underground space, and tunnel engineering's buried depth is increasing, resulting in higher and higher in-situ stress environments. Compared with the creep-mechanical behavior of soft rock, the hard rock under a high-stress level is prone to rockburst, posing considerable challenges [1,2]. For example, in Sichuan, a mountainous province in the west of China, the phenomenon of high in-situ stress exists in the deep and long tunnels that serve as the expressway's control engineering, and the majority of them encounter the problem of rockburst [1-4]. Among the railway tunnels, Sichuan-Tibet Railway has a high in-situ stress level which is extremely rare in the history of railway tunnel construction, which is expected to exceed $70 \mathrm{MPa}$. Rockburst also occurs frequently in underground projects in the field of hydropower, such as the diversion tunnels of Yuzixi level 1 and 2 hydropower stations, Baihetan Taiping Yi, Ertan, Tianshengqiao, and Jinping level 2 hydropower stations, etc. [5-7]. Rockburst not only damages construction equipment and slows construction progress, but also endangers the lives and safety of on-site workers [8].

Rockburst disasters in tunnels are extremely destructive and unpredictable, so enough attention must be paid to tunnels where rockburst may occur. Many types of research 
on rockburst mainly focus on mechanism research, prediction and early warning, and instability control of rockburst [9-15]. Among them, appropriate supporting structures are an important part of rockburst-tunnel instability control. However, there are relatively few research results on the design method of rockburst tunnel supporting structures.

At present, more and more calculation methods of tunnel deformation have been proposed [16], the design methods of deep-buried hard rock tunnels for drilling, blasting, anchoring, and grouting in various countries are mainly divided into engineering analogy, load-structure, layer-structure, and theoretical calculation method. Among them, the stratiform-structure method and theoretical calculation method are affected by uncertain factors such as design parameters and supporting structure, and the support design process is more complex. To a large extent, it still depends on practical design. The design of rockburst tunnel supporting structures in China and other countries focuses mainly on engineering analogy. In practical engineering, the stratiform-structure method is used for verification and analysis.

The load-structure method has been widely adopted in some countries, such as China, Japan, Germany, etc. [17] because of its simple physical model, comprehensive analysis of various loads and rock mass states, and fast calculation speed. The determination of load is essential in this design method. However, through theauthor's investigation, there is no complete calculation method to estimate the impact load acting on the supporting structure of the rockburst tunnel. Therefore, to adopt a load-structure method in designing rockburst tunnel supporting structures, it is necessary to conduct an in-depth study on its impact load.

Therefore, based on the data research and theoretical analysis method, from the perspective of energy and using the method of structural mechanics, this paper deduces the calculation formula of the impact load acting on the supporting structure of the rockburst tunnel. In addition, the rockburst-prone parts of the circular tunnel and the horseshoe tunnel are studied utilizing theoretical analysis, numerical simulation, and data investigation. Finally, the local load-structure model of the rockburst tunnel and its calculation flow is derived.

\section{Calculation Method of Impact Load in the Rockburst Tunnel}

The calculation method of impact load acting on the supporting structure mainly includes three parts: the amount of kinetic energy released, the size and velocity of the blasting block, and the load acting on the supporting structure. Firstly, the strain energy stored in the rock mass and the kinetic energy of the explosive block transformed from the released energy are calculated employing energy analysis. Secondly, the size and velocity of the blasting block are determined. Finally, after obtaining the two key parameters, the size and velocity of the blasting block, the load acting on the supporting structure is estimated by the structural mechanic's method.

\subsection{Surrounding Rock Strain Energy of Tunnel}

According to the material mechanics and elasticity mechanics, it can be known that the strain energy of the surrounding rock in triaxial stress state can be calculated according to Equation (1), which is the calculation formula of elastic strain energy of surrounding rock per unit volume expressed by stress tensor.

$$
\left\{\begin{array}{l}
U=\frac{1}{2 E}\left[(1+\mu) \sigma_{i j} \sigma_{j i}-\mu \Theta^{2}\right] \\
\Theta=\sigma_{11}+\sigma_{22}+\sigma_{33}
\end{array}\right.
$$

where $U$ is the strain energy density of surrounding rock, $E$ and $u$ are the elastic modulus and Poisson's ratio of surrounding rock, respectively.

In the secondary stress state after tunnel excavation, the directions of the three stress spindles are, respectively, the tangent direction of the excavation contour plane, the axial 
direction of the tunnel and the normal direction of the contour plane, and $\sigma_{3}=0$ near the contour plane.

It can be known that the strain energy formula of surrounding rock surrounding the tunnel after excavation is as follows:

$$
U=\frac{1}{2 E}\left[\sigma_{1}^{2}+\sigma_{2}^{2}-2 \mu \sigma_{1} \sigma_{2}\right]
$$

In terms of vertical initial ground stress and lateral pressure coefficient,

$$
U=\frac{1-\mu^{2}}{2 E} \sigma_{1}^{2}=\frac{1-\mu^{2}}{2 E} \sigma_{v}^{2}(1+\lambda+2(1-\lambda) \cos 2 \theta)^{2}
$$

With different $\theta$ values, the formula for calculating the strain energy density contained in the vault, shoulder, waist, side wall, and inverted supply of the tunnel under different initial vertical stresses and lateral pressure coefficients can be obtained:

Vault and invert: $\theta=90^{\circ}$

$$
U=\frac{1-\mu^{2}}{2 E} \sigma_{v}^{2}(3 \lambda-1)^{2}
$$

Arch shoulders and side walls: $\theta=45^{\circ}$

$$
U=\frac{1-\mu^{2}}{2 E} \sigma_{v}^{2}(1+\lambda)^{2}
$$

Hence: $\theta=0^{\circ}$

$$
U=\frac{1-\mu^{2}}{2 E} \sigma_{1}^{2}=\frac{1-\mu^{2}}{2 E} \sigma_{v}^{2}(3-\lambda)^{2}
$$

\subsection{Determination of Released Kinetic Energy}

In the process of rock failure, shown in Figure 1, energy stored in rock mass will not be completely released as kinetic energy, some will be dissipated in the form of thermal energy and surface energy. Different scholars have derived the calculation formula of dissipated energy, respectively. However, the calculation formula contains many parameters that are difficult to obtain in specific projects, and the calculation is complex. In this paper, the specific size of energy other than kinetic energy is not considered, and, instead, the focus is on how much of the strain energy stored in a rock mass can be converted into kinetic energy and released in the way of rockburst.

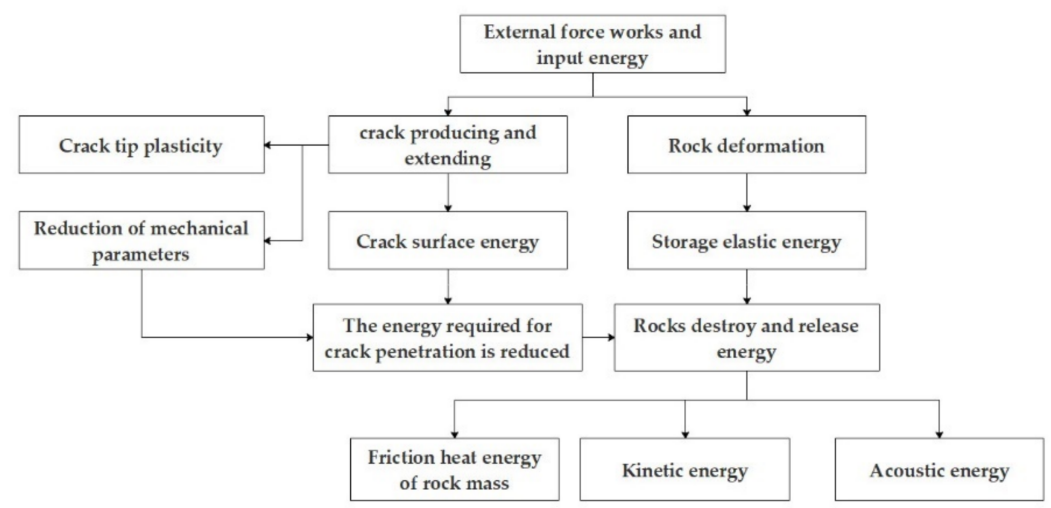

Figure 1. Transformation and transfer relations among various energies in the process of rock de-formation and failure.

The calculation of the released kinetic energy involves two processes. The first process is external force doing work, and energy being accumulated in the rock mass. Here, some 
energy will be used to expand the cracks between degraded surrounding rocks. When the critical condition is reached, rockburst occurs and energy is released, this part of the energy will not be released. The strain energy contained in the surrounding rock includes elastic strain energy and plastic strain energy. The other process is that when rockburst occurs, a part of the energy is released in the form of acoustic energy and thermal energy, rather than all in the form of kinetic energy. The following analyzes the two processes, respectively, to determine the kinetic energy that can be released during rockburst.

The energy release rate of the first process can be determined by experimental methods, which refer to the acquisition method of the rockburst tendency index, customarily expressed as $W_{\text {et }}$ (also known as elastic energy index in China) in the Polish national standard [17]. In the uniaxial compressive-strength test of rock, the specimen is loaded to $70-80 \%$ of its peak strength and then unloaded 0.05 times. In the process of loading and unloading tests, the stress-strain curves of loading and unloading of rocks under uniaxial stress state can be finally obtained, to calculate the ratio between the elastic strain energy released by unloading $\left(\Phi_{S P}\right)$ and the strain energy consumed $\left(\Phi_{S T}\right)$, which is known as the rockburst tendency index $\left(W_{e t}\right)$ :

$$
W_{e t}=\Phi_{S P} / \Phi_{S T}
$$

The test curve of the rockburst tendency index is shown in Figure 2:

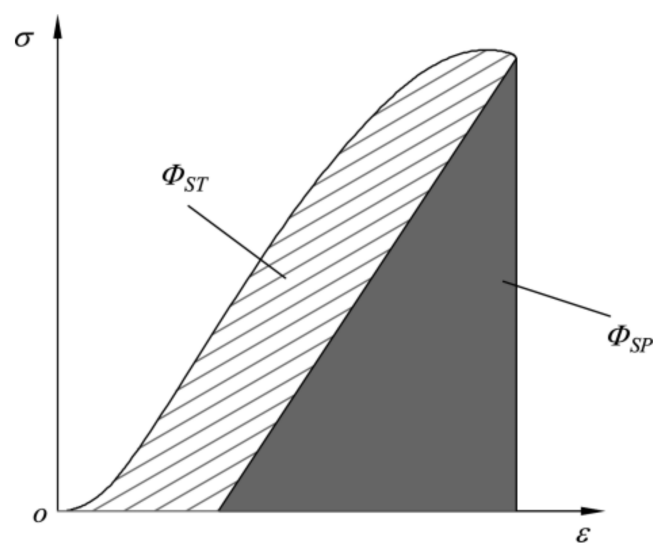

Figure 2. The test curve of $W_{e t}$.

According to the definition of the rockburst tendency index, the value of $W_{\text {et }}$ reflects the relationship between the energy stored in rock and released during rockburst, that is, the relationship between the sum of elastic strain energy and plastic strain energy. In the same state, the higher the $W_{\text {et }}$ value, the greater the energy stored in the rock, the greater the energy it can release, and there is a higher possibility of higher-grade rockburst.

According to the Polish national standard, the values of $W_{e t}$ corresponding to different grades of rockburst are as follows [18]:

$W_{e t} \geq 5.0$, Severe and extremely severe grade;

$2.0 \leq W_{e t}<5.0$, Mild and medium grade;

$W_{\text {et }}<2.0$, No rockburst.

In different grades of rockburst, different $W_{e t}$ values are selected to calculate the proportion of elastic strain energy in all strain energy contained in the rock mass. When the test conditions are available, the surrounding rock of a specific tunnel engineering site should be used for rock uniaxial compressive strength test to obtain the values of $W_{\text {et }}$. Then, the proportion of elastic strain energy is determined under the surrounding rock condition.

In case of a lack of test conditions, the recommended value can be obtained according to Table 1 regarding Polish national standards. 
Table 1. The proportion of elastic strain energy of surrounding rock under different grades of rockburst.

\begin{tabular}{cccc}
\hline Rockburst Grade & $\boldsymbol{W}_{\boldsymbol{e}}$ & The Proportion of Elastic Strain Energy & Recommended Values \\
\hline mild & $<2$ & $<66.7 \%$ & $65 \%$ \\
medium & $2 \sim 3.5$ & $66.7 \sim 77.8 \%$ & $73 \%$ \\
severe & $3.5 \sim 5$ & $77.8 \sim 83.3 \%$ & $80 \%$ \\
extremely severe & $>5$ & $>83.3 \%$ & $85 \%$ \\
\hline
\end{tabular}

In the second process, the proportion of kinetic energy in all elastic strain energy released can refer to [17], which shows the relationship between the proportion of kinetic energy in various energy released during rock shear failure and the internal friction angle in Figure 3.

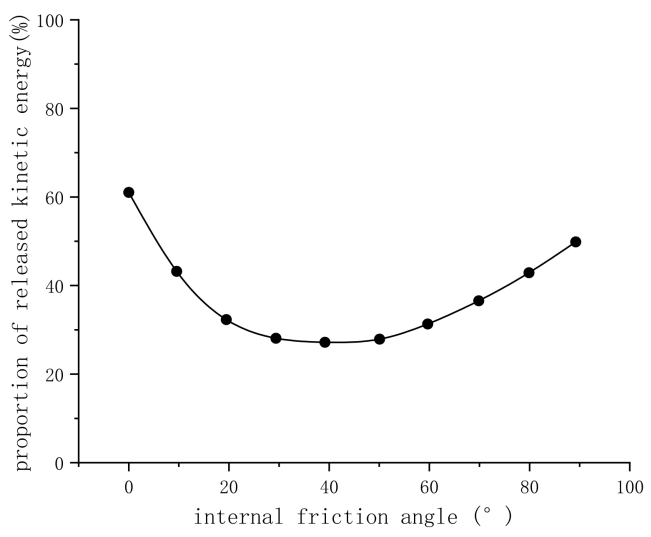

Figure 3. The relationship between released kinetic energy and the internal friction angle.

As shown in Figure 3, the proportion of kinetic energy in the released energy is the smallest when the internal friction angle is $45^{\circ}$, accounting for only $30 \%$. As the internal friction angle approaches $0^{\circ}$ and $90^{\circ}$, the proportion of kinetic energy gradually increases until it reaches the maximum value, $60 \%$. The internal friction angle is given, the value can be taken according to Figure 3. In case of lack of data, it can be taken as $60 \%$ according to the most unfavorable situation.

\subsection{Subsection}

The characteristics of blasting blocks in different types of rockburst are given in the literature [19]. Generally speaking, it is a conch shell or flake in exfoliation rockburst, an elongated elliptic fragment in slight-ejection rockburst, and a block in burst rockburst. The main mode of rockburst is exfoliation in mild and medium grades and ejection in extremely severe grades. Exfoliation rockburst may occur several times, so it can not completely reflect the whole process if only the characteristics of a single rockburst are counted. Meanwhile, exfoliation can also be understood as ejection with a small velocity. In addition, the blasting blocks of ejection rockburst are not complete, more than one block can be ejected from the same blasting pit at a time, and some blocks will break into several pieces after landing. It is more reasonable to comprehensively analyze and calculate the size of the blasting block from the perspective of the blasting pit.

To study the characteristics of blasting pits, 14 tunnels in different countries were investigated $[19,20]$, as shown in Table 2.

Based on Table 2, the shape of the blasting pit can be divided into three categories: V-shape (including ladder shape, right-angle shape, and wedge shape), dome shape (including arc long groove and dome shape), and nest shape (including nest shape, honeycomb shape, and pot bottom shape). Using the tunnel as the basic unit, each tunnel contains 
one or two main blasting pit shapes, and the proportion of each blasting pit shape can be calculated, as illustrated in Figure 4.

Table 2. Statistics of craters of different rockburst tunnels.

\begin{tabular}{|c|c|c|c|c|}
\hline Code & Tunnel Name & Mileage & Rockburst Grade & Characteristics of Blasting Pit \\
\hline 1 & Futangba highway tunnel & $\mathrm{K} 46+964 \sim \mathrm{K} 46+944$ & severe & Arc long groove \\
\hline 2 & Futangba highway tunnel & $\mathrm{K} 46+613.5 \sim \mathrm{K} 46+581$ & severe & Arc long groove \\
\hline 3 & Futangba highway tunnel & $\mathrm{K} 46+964 \sim \mathrm{K} 46+581$ & medium & Large scale continuous distribution \\
\hline 4 & Futangba highway tunnel & $\mathrm{K} 46+964 \sim \mathrm{K} 46+581$ & mild & Small scale sporadic distribution \\
\hline 5 & Diversion tunnel of & & & 5 \\
\hline 6 & Diversion tunnel of & & & 6 \\
\hline 27 & $\begin{array}{l}\text { Diversion Tunnel of } \\
\text { SQirehatar Hydropower Station }\end{array}$ & - & - & Mainly V-shape \\
\hline
\end{tabular}

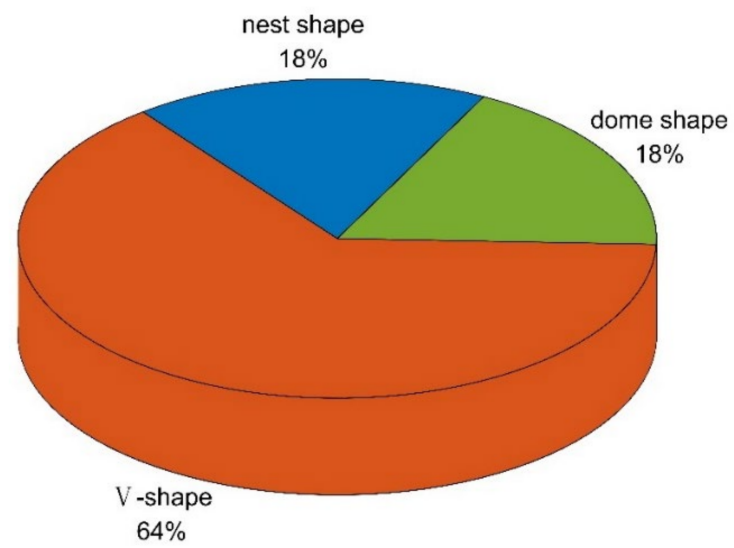

Figure 4. The proportion of different blasting pit shapes.

As shown in Figure 4, the V-shaped blasting pit is the most common, accounting for $64 \%$ of all blasting pits. Therefore, in the subsequent calculation of blasting block volume, the blasting pit is considered as a V-shaped blasting pit a whereas the blasting block is considered as the corresponding cone. Figure 5 is a photo of a V-shaped blasting pit at the rockburst site.

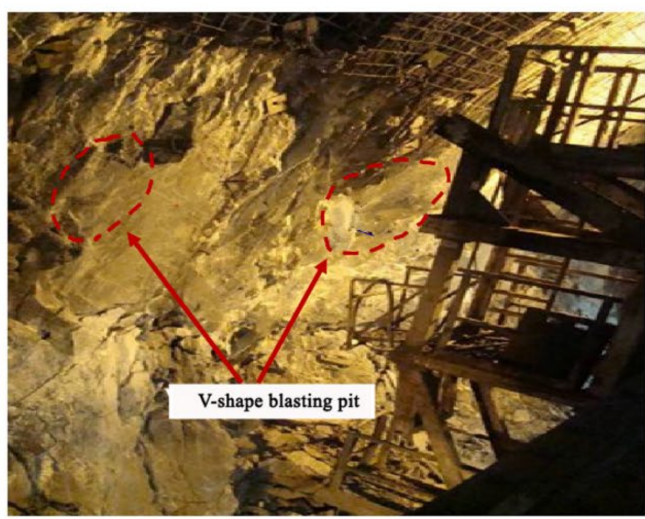

(a)

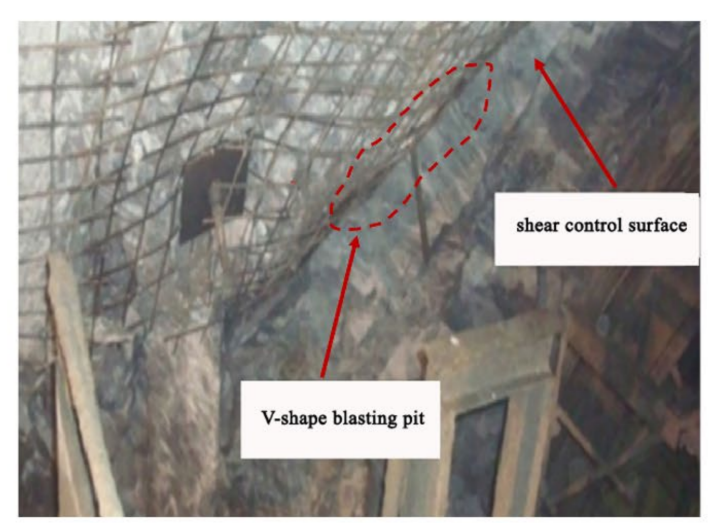

(b)

Figure 5. V-shaped blasting pit at the rockburst site: (a) V-shape blasting pit without supporting structure; (b) V-shape blasting pit with supporting structure. 
It is important to note that the blasting block is not necessarily the shape of the scattered blocks we see after the rockburst. The impact of the blasting block may also form the final shape after it falls to the ground.

To study the influence depth under different grades of rockburst, 166 rockburst sections of seven tunnels such as the Futangba highway tunnel are counted [20], and the statistical results are shown in Table 3.

Table 3. Statistical table of influence depth of rockburst of different grades.

\begin{tabular}{|c|c|c|c|c|c|}
\hline Number & Tunnel Name & Mileage & Length/Times & Grade & Influence Depth \\
\hline 1 & \multirow[t]{2}{*}{ Futangba highway tunnel } & $\mathrm{K} 46+964 \sim \mathrm{K} 46+944$ & $20 \mathrm{~m}$ & severe & $\begin{array}{l}\text { average: } 1.0 \mathrm{~m} \text {; } \\
\text { maximum: } 1.5 \mathrm{~m}\end{array}$ \\
\hline 2 & & $\mathrm{~K} 46+613.5 \sim \mathrm{K} 46+581$ & $32.5 \mathrm{~m}$ & severe & $\begin{array}{l}\text { average: } 1.5 \mathrm{~m} ; \\
\text { maximum: } 2.0 \mathrm{~m}\end{array}$ \\
\hline 3 & \multirow{3}{*}{ Erlangshan highway tunnel } & $\mathrm{K} 260+080 \sim \mathrm{K} 260+240$ & $160 \mathrm{~m}$ & mild & $0.5 \mathrm{~m}$ \\
\hline 4 & & $\mathrm{~K} 260+270 \sim \mathrm{K} 260+330$ & $60 \mathrm{~m}$ & mild & $0.5 \mathrm{~m}$ \\
\hline 5 & & $\mathrm{~K} 260+996 \sim \mathrm{K} 261+015$ & $19 \mathrm{~m}$ & severe & $2 \mathrm{~m}$ \\
\hline 6 & $\begin{array}{l}\text { Long exploratory tunnel of } \\
\text { Jinping II Hydropower Station }\end{array}$ & $4000 \mathrm{~m}$ & 61 times & mild, medium & $\begin{array}{l}\text { mainly: } 10 \sim 30 \mathrm{~cm} ; \\
\text { maximum: } 55 \mathrm{~cm}\end{array}$ \\
\hline 164 & \multirow{3}{*}{$\begin{array}{l}\text { Diversion Tunnel of } \\
\text { SqCirehatar Hydropower Station }\end{array}$} & $10,521 \sim 10,530$ & & mild & $20 \sim 30 \mathrm{~cm}$ \\
\hline 165 & & $10,521 \sim 10,530$ & & mild & $20 \mathrm{~cm}$ \\
\hline 166 & & $11,170 \sim 11,190$ & $20 \mathrm{~m}$ & mild & $50 \mathrm{~cm}$ \\
\hline
\end{tabular}

The influence depth of blasting pit under different rockburst grades is shown in Table 4 .

Table 4. Influence depth of rockburst.

\begin{tabular}{ccccc}
\hline Rockburst Grade & Mild & Medium & Severe & Extremely Severe \\
\hline Influence depth & $<0.5 \mathrm{~m}$ & $0.5 \mathrm{~m} \sim 1 \mathrm{~m}$ & $1 \mathrm{~m} \sim 3 \mathrm{~m}$ & $>3 \mathrm{~m}$ \\
\hline
\end{tabular}

The influence depth of various rockburst grades is chosen, and the volume of the blasting block can be calculated using the shape of a square cone. Rockburst mainly occurs in hard rocks such as granite, limestone, marble, and gneiss. In specific projects, on-site rocks should be selected to test their density. When the test is not available on-site, it can be taken as $2.75 \mathrm{t} / \mathrm{m}^{3}$ because of the slight difference in density of the above rock masses. The mass of the blasting block can be obtained finally by multiplying the density by the volume.

After the released kinetic energy and the mass of the blasting block are determined, the velocity of the blasting block can be obtained by the kinetic energy formula.

The kinetic energy formula:

$$
E_{k}=\frac{m v^{2}}{2}
$$

where $E_{k}$-kinetic energy of the blasting block $(\mathrm{J})$; $m$ - a mass of the blasting block $(\mathrm{kg})$; $V$-velocity of blasting block $(\mathrm{m} / \mathrm{s})$.

$$
v=\sqrt{\frac{2 E_{k}}{m}}
$$

The velocity of the blasting block obtained by calculating shall conform to the actual situation. Therefore, the research on the velocity of the blasting block is carried out. From the perspective of energy balance, Zuo et al. [21] studied the velocity of the blasting block by combining static loading and dynamic loading. McGarr [22] studied the velocity of the blasting block from the buckling instability of the beam. In addition, the maximum velocity of blasting blocks observed at different sites is $10 \mathrm{~m} / \mathrm{s}[23,24]$. According to the extensive research into various aspects, the maximum velocity of blasting blocks can exceed $10 \mathrm{~m} / \mathrm{s}$, but only in rare cases.

\subsection{Dynamic Load Factor}

The blasting block acts on the supporting structure at a certain velocity to cause deformation. In this process, the change of blasting block height is the vertical component of the displacement value of the supporting structure at its action point, and the displacement 
value is minimal. Therefore, the change of gravitational potential energy of the blasting block is so small that it does not have to be considered. All the kinetic energy of the blasting block is transformed into the strain energy of the structure.

Kinetic energy: $E_{k}=\frac{m v^{2}}{2}$; strain energy: $V_{d}=\frac{F \Delta}{2}$. They are equal:

$$
\frac{m v^{2}}{2}=\frac{F \Delta}{2}
$$

where $F$-maximum impact force $(\mathrm{kN}) ; \Delta$-maximum deflection of impact site $(\mathrm{mm})$.

According to structural mechanics, when the supporting structure is considered as a linear elastic system, it can be known that $F$ and $\Delta$ should meet the relationship shown in Equation (11):

$$
\Delta=\frac{K_{0} F}{E I}
$$

where E-Elastic modulus of supporting structure; I-Sectional bending coefficient; $K_{0}$-Support dimension coefficient.

In the formula, support dimension coefficient $K_{0}$ is a coefficient related to support section size and support section type, reflecting the difference of load-deformation relationship between different tunnel sections. When the tunnel is circular, it can be calculated according to Equation (12):

$$
K_{0}=\frac{\pi-3}{2} R^{2}
$$

where $R$-Equivalent radius of tunnel (m).

The simultaneous Formulas (10)-(12) can be solved as follows:

$$
\left\{\begin{array}{l}
\Delta=\sqrt{\frac{K_{0} m v^{2}}{E I}} \\
F=\sqrt{\frac{m v^{2} E I}{K_{0}}}
\end{array}\right.
$$

where $\Delta$-Maximum deflection of impact site $(\mathrm{mm}) ; F$-Impact load expressed in the form of concentrated load $(\mathrm{kN})$.

It can also be expressed by kinetic energy:

$$
F=\sqrt{\frac{2 E_{k} V E I}{K_{0}}}
$$

where $E_{k}$-Released kinetic energy per unit volume of surrounding rock (J); $V$-Volume of surrounding rock releasing kinetic energy $\left(\mathrm{m}^{3}\right)$.

In structural dynamics, dynamic load factor $K$ is used to represent the action of dynamic load. The dynamic load factor represents the ratio of the deformation of the structure under dynamic load to the deformation of the structure under self-weight. Moreover, it can also be expressed as the multiple of the impact load equivalent to the self-weight.

$$
K=\frac{F}{m g}=\frac{\Delta}{\Delta_{s t}}=\sqrt{\frac{v^{2} E I}{K_{0} m g^{2}}}
$$

According to Equation (15), the dynamic load factor of impact load acting on the supporting structure is related to the stiffness of the supporting structure. Therefore, the impact load on the supporting structure is different depending on the supporting parameters.

It should be noted that when the supporting structure is considered as a linear elastic system, Equations (13)-(15) are universal. They are not only applicable to circular tunnels but also railway or highway structures with sectional shapes such as three-center circles and four-center circles. Different section sizes and different section types correspond to different support size coefficients $K_{0}$. 


\subsection{Impact Load}

Increase the self-weight of blasting block to multiple of the dynamic load factor, and act on the structure in the form of uniform load, which can be equivalent to the impact load.

$$
q=\frac{K m g}{a^{2}}
$$

Alternatively, expressed in the form of kinetic energy:

$$
q=\sqrt{\frac{2 E_{k} V E I}{K_{0} a^{4}}}
$$

where $q$-Impact load (Pa); $a$-length of a side of the blasting block (m).

The underlying principles of both expressions are the same. The significance of using different expressions is that the expression of Equation (16) is more concise, but it requires many assumptions. When the rockburst on site is different from the assumptions, the application of this equation will be limited. The expression of Equation (17) is more basic. In addition, when on-site parameters are different from the assumption, the relevant parameters can be directly adjusted to be more appropriate for the on-site situation, however the expression is complicated as a result.

\section{The Acting Location of Impact Load in the Rockburst Tunnel}

The impact load is the local load, applied to the location where rockburst is most likely to occur in the surrounding rock of the tunnel, or the location where the damage degree is the largest after rockburst occurs. Therefore, in this section, the authors research the acting location of impact load in circular tunnels and horseshoe tunnels.

\subsection{Calculation Model and Calculation Parameters}

The calculation model includes two section sizes, single-track tunnel, and double-track tunnel, and two-section types, circular section and horseshoe section, for each section. The section size and calculation model are shown in Figure 6.

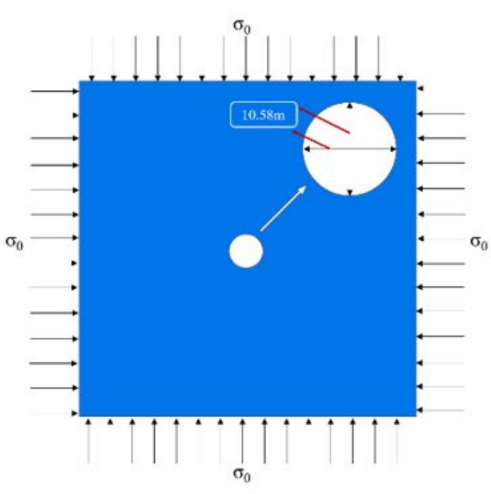

(a)

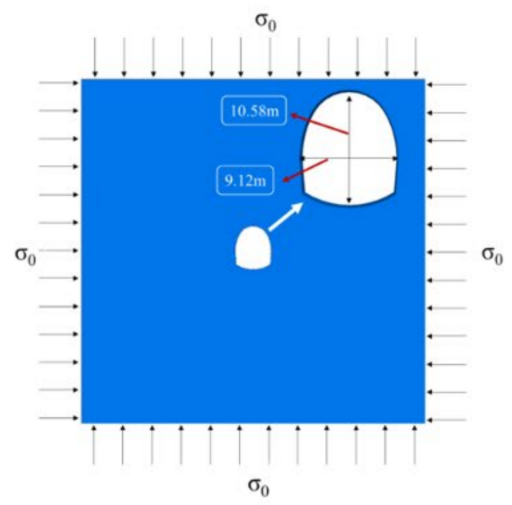

(b)

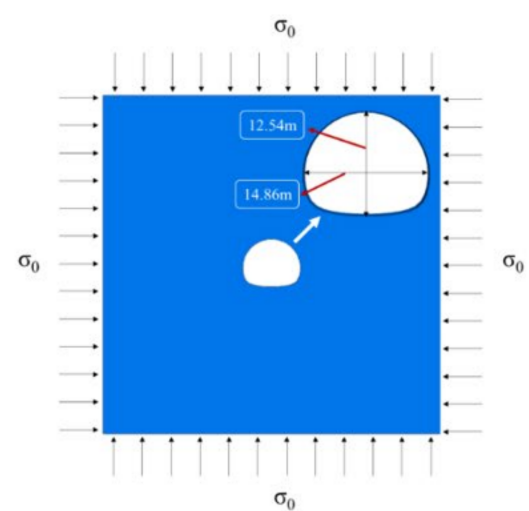

(c)

Figure 6. Numerical calculation model: (a) Circular; (b) Single-track; (c) Double-track.

Considering in-situ stress, section type, and lateral pressure coefficient, 18 working conditions are combined. The specific calculation conditions are listed in Table 5, and the numerical calculation parameters are shown in Table 6. 
Table 5. Calculation condition table.

\begin{tabular}{|c|c|c|c|}
\hline Section Type & In-Situ Stress (MPa) & Lateral Pressure Coefficient & Calculation Times \\
\hline \multirow{7}{*}{ Circular tunnel } & \multirow{4}{*}{$30 \mathrm{MPa}$} & $\lambda=0.5$ & 1 \\
\hline & & $\lambda=1$ & 1 \\
\hline & & $\lambda=1.5$ & 1 \\
\hline & & $\lambda=0.5$ & 1 \\
\hline & \multirow{3}{*}{$40 \mathrm{MPa}$} & $\lambda=1$ & 1 \\
\hline & & $\lambda=1.5$ & 1 \\
\hline & & $\lambda=0.5$ & 1 \\
\hline \multirow{4}{*}{ Single-track } & \multirow{3}{*}{$30 \mathrm{MPa}$} & $\lambda=1$ & 1 \\
\hline & & $\lambda=1.5$ & 1 \\
\hline & & $\lambda=0.5$ & 1 \\
\hline & \multirow[t]{3}{*}{$40 \mathrm{MPa}$} & $\lambda=1$ & 1 \\
\hline \multirow{8}{*}{ Double-track } & & $\lambda=1.5$ & 1 \\
\hline & & $\lambda=0.5$ & 1 \\
\hline & \multirow[t]{2}{*}{$30 \mathrm{MPa}$} & $\lambda=1$ & 1 \\
\hline & & $\lambda=1.5$ & 1 \\
\hline & & $\lambda=0.5$ & 1 \\
\hline & \multirow[t]{2}{*}{$40 \mathrm{MPa}$} & $\lambda=1$ & 1 \\
\hline & & $\lambda=1.5$ & 1 \\
\hline & Total & & 18 \\
\hline
\end{tabular}

Table 6. Physical and mechanical parameters of surrounding rock.

\begin{tabular}{ccccccc}
\hline Lithology & $\begin{array}{c}\text { Average Unit } \\
\text { Weight }\left(\mathbf{k N} / \mathbf{m}^{3}\right)\end{array}$ & $\begin{array}{c}\text { Elasticity } \\
\text { Modulus (GPa) }\end{array}$ & Poisson's Ratio & Cohesion (MPa) & $\begin{array}{c}\text { Internal Friction } \\
\text { Angle }\left(^{\circ}\right)\end{array}$ & $\begin{array}{c}\text { Uniaxial Compressive } \\
\text { Strength (MPa) }\end{array}$ \\
\hline Granite & 26.9 & 33 & 0.23 & 2 & 54 & 90.48 \\
\hline
\end{tabular}

The commonly used E. Hoek determination method [25] is selected to judge rockburst level by the ratio of the maximum tangential stress of tunnel section to the uniaxial compressive strength of rock, as shown in Formula (18).

$$
\left\{\begin{array}{l}
\sigma_{\theta} / R_{c}<0.42 \text { (Mild grade) } \\
0.42 \leq \sigma_{\theta} / R_{c}<0.56 \text { (Medium grade) } \\
0.56 \leq \sigma_{\theta} / R_{c}<0.7 \text { (Severe grade) } \\
\sigma_{\theta} / R_{c} \geq 0.7 \text { (Extremely severe grade) }
\end{array}\right.
$$

where $\sigma_{\theta}$-Maximum tangential stress of tunnel section; $R_{\mathcal{c}}$-Uniaxial compressive strength of rock.

\subsection{Analysis of the Acting Location of Impact Load}

\subsubsection{Circular Tunnel}

The calculated maximum tangential stress of the tunnel section cannot directly reflect the occurrence range of rockburst. To have an intuitive display effect, the product of the determination coefficient in the limit state and the uniaxial compressive strength of rock are taken as the critical tangential stress of rockburst, and its contour line is drawn in the figure to obtain the occurrence range of rockburst of different grades. The occurrence range of extremely severe rockburst after treatment is shown in Figures 7 and 8.

Figures 7 and 8 reveal that, with the increase of in-situ stress, the influence depth in the surrounding rock where rockburst may occur gradually increases. However, the location where the influence depth is the deepest does not change with the increase of in-situ stress. No matter what the in-situ stress is, when $\lambda=1$, the depth where rockburst may occur in the whole ring of the tunnel is the same; but when $\lambda=0.5$, the depth where rockburst may occur at the tunnel arch waist is deepest; also, when $\lambda=1.5$, the depth where rockburst may occur at the tunnel vault and invert is most resounding. The relevant conclusions are consistent with the theoretical analysis in the previous section. 


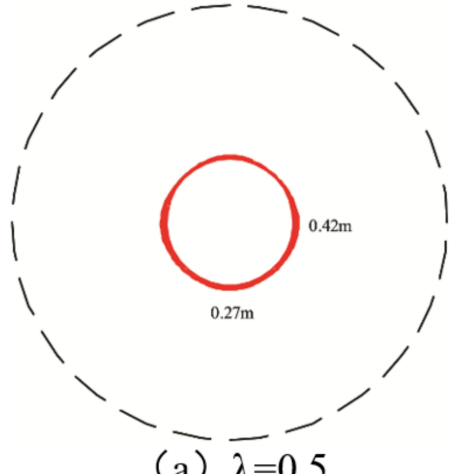

(a) $\lambda=0.5$

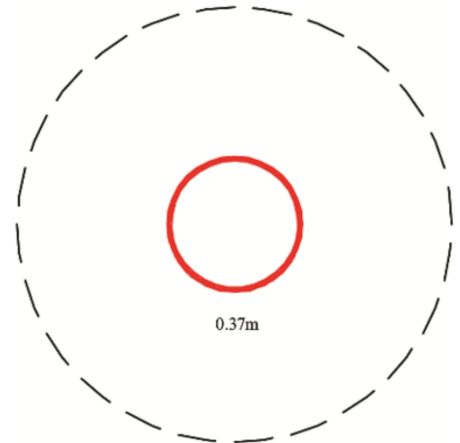

(b) $\lambda=1$

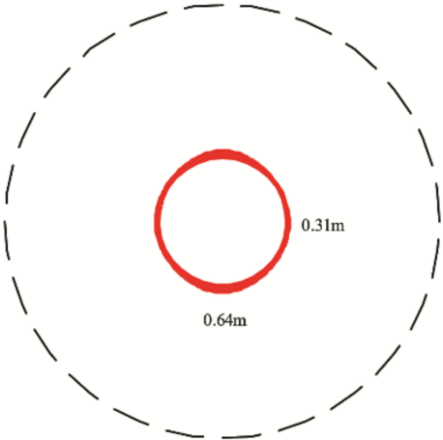

(c) $\lambda=1.5$

Figure 7. Range of extremely strong rockburst when $\sigma_{\mathrm{v}}=30 \mathrm{Mpa}$ : (a) $\sigma_{\mathrm{H}} / \sigma_{\mathrm{v}}=0.5 ;(\mathbf{b}) \sigma_{\mathrm{H}} / \sigma_{\mathrm{v}}=1.0$; (c) $\sigma_{\mathrm{H}} / \sigma_{\mathrm{v}}=1.5$.

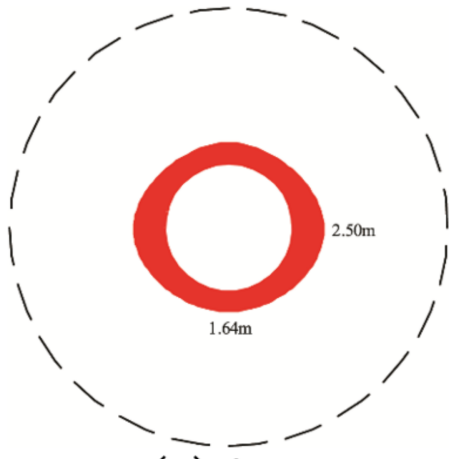

(a) $\lambda=0.5$

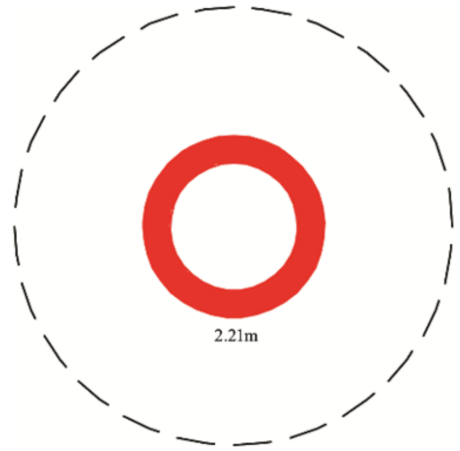

(b) $\lambda=1$

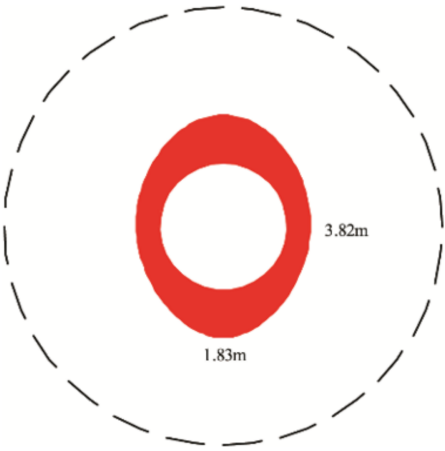

(c) $\lambda=1.5$

Figure 8. Range of extremely strong rockburst when $\sigma_{\mathrm{v}}=40 \mathrm{Mpa}$ : (a) $\sigma_{\mathrm{H}} / \sigma_{\mathrm{v}}=0.5 ;(\mathbf{b}) \sigma_{\mathrm{H}} / \sigma_{\mathrm{v}}=1.0$; (c) $\sigma_{\mathrm{H}} / \sigma_{\mathrm{v}}=1.5$.

The construction drainage tunnel of Jinping II hydropower station is a circular tunnel with complete surrounding rock and few structural planes. The buried depth of the drainage tunnel is generally significant. Except that gravity and structural stress act together within a certain range at the inlet and outlet, most of the tunnels are mainly gravity stress. Statistics were made on 137 parts where rockburst occurred in 115 sections ofdrainage tunnels [26], as shown in Table 7.

Table 7. Location statistics of rockburst in a construction drainage tunnel.

\begin{tabular}{cccc}
\hline Number & Mileage & Rockburst Grade & Location \\
\hline 1 & SK14 $+441.00 \sim 14+426.00$ & severe & right wall \\
2 & SK14 $+415.00 \sim 14+390.00$ & severe & right wall \\
3 & SK14 $+415.00 \sim 14+390.00$ & severe & left wall, vault \\
4 & SK14 $+252.00 \sim 14+250.00$ & medium & right spandrel \\
5 & SK14 $+251.00 \sim 14+245.00$ & severe & right spandrel \\
6 & SK14 $+230.00 \sim 14+227.00$ & severe & right spandrel \\
7 & SK14 $+226.00 \sim 14+224.00$ & medium & left spandrel \\
8 & SK14 $+222.00 \sim 14+220.00$ & medium & right spandrel \\
9 & SK13 $+039.00 \sim 13+043.00$ & mild & left spandrel \\
114 & SK9 $+877.00 \sim 9+875.00$ & severe & Vault, spandrel \\
115 & SK9 $+872.00 \sim 9+869.00$ & severe & spandrel, left wall \\
\hline
\end{tabular}

The location is divided into three parts: spandrel, arch waist, and vault, and the proportion of rockburst in each part is shown in Figure 9. 


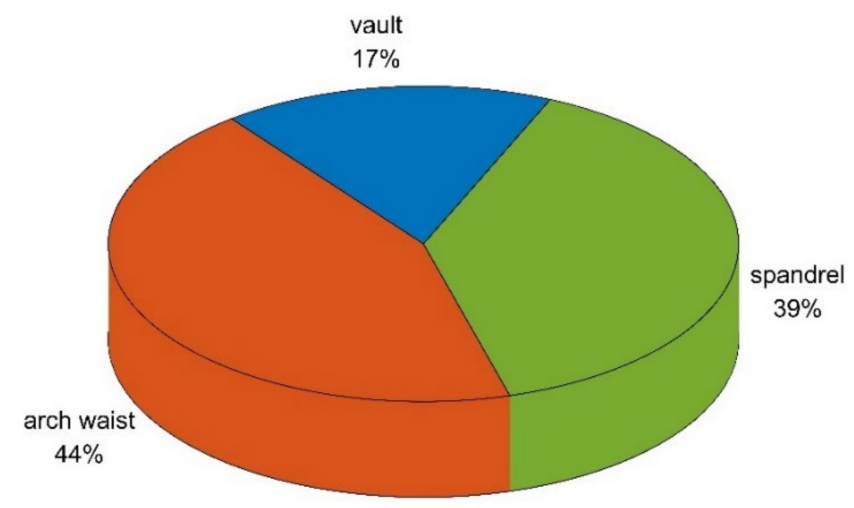

Figure 9. Statistics of rockburst locations.

As shown from Table 7 and Figure 9, the frequency of rockburst in different parts is arch waist $>$ spandrel $>$ vault. Considering that the in-situ stress is mainly gravity, the conclusion is consistent with the previous two sections.

\subsubsection{Subsubsection}

The same method can be used to study the location where rockburst most likely occurs in horseshoe tunnels under different in-situ stress and different lateral pressure coefficients. The rockburst occurrence range is treated in the same way as the circular tunnel. Severe rockburst is represented in blue, and extremely severe rockburst is represented in red, the occurrence range of severe and extremely severe rockburst in single-track and double-track tunnels can be obtained after treatment, as shown in Figures 10-13.

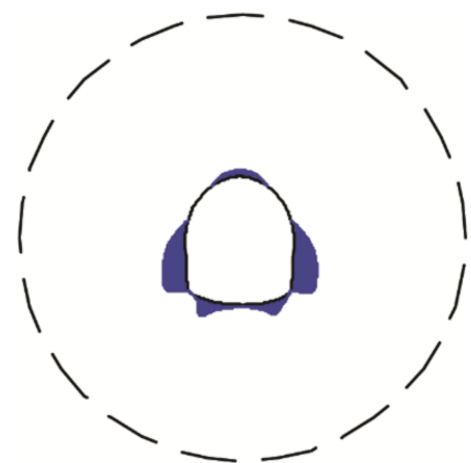

(a) $\lambda=0.5$

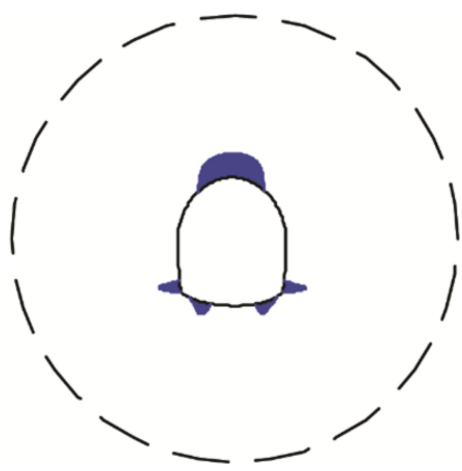

(b) $\lambda=1$

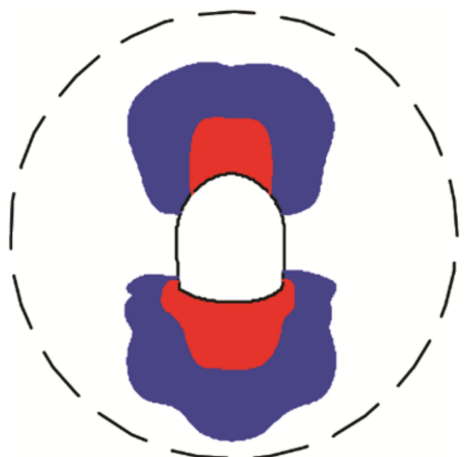

(c) $\lambda=1.5$

Figure 10. Range of strong and extremely strong rockburst in a single-track tunnel when $\sigma_{\mathrm{v}}=30 \mathrm{MPa}$.
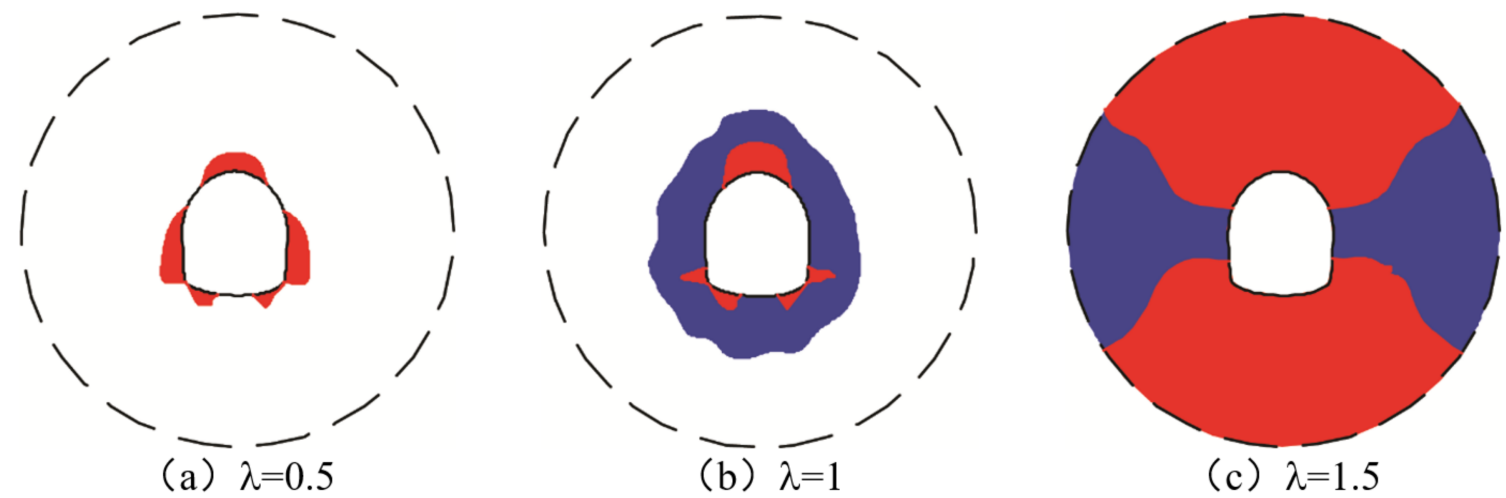

Figure 11. Range of strong and extremely strong rockburst in a single-track tunnel when $\sigma_{\mathrm{v}}=40 \mathrm{MPa}$. 

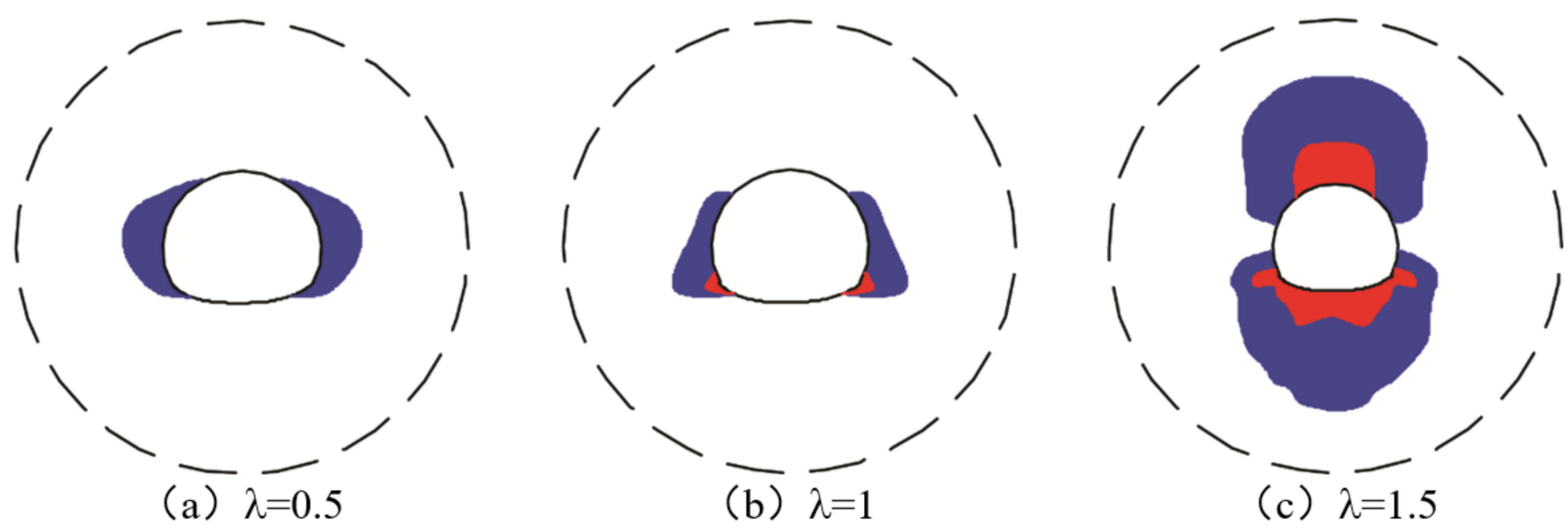

Figure 12. Range of strong and extremely strong rockburst in a double-track tunnel when $\sigma_{\mathrm{v}}=30 \mathrm{MPa}$.
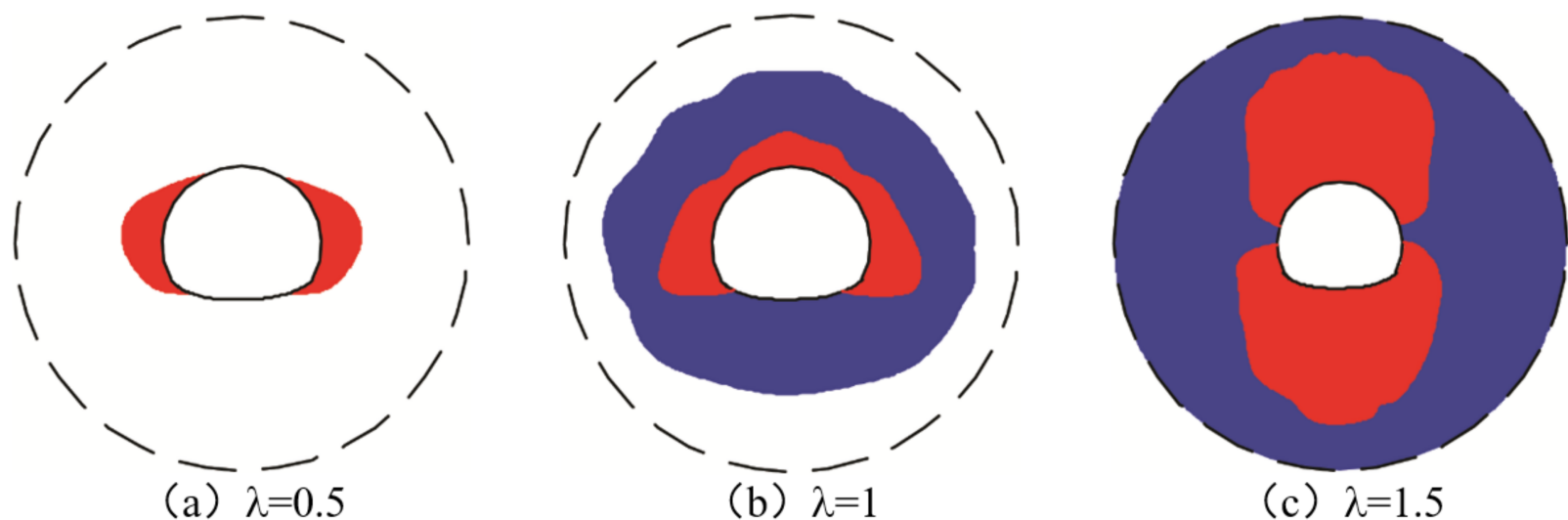

Figure 13. Range of strong and extremely strong rockburst in a double-track tunnel when $\sigma_{\mathrm{v}}=40 \mathrm{MPa}$.

As can be seen from Figures 10-13, when the in-situ stress is mainly vertical, the most damaged parts are the side wall and arch waist; when the vertical stress and horizontal stress are equal, the most damaged parts are different between single-track tunnels and double-track tunnels: damage degree of a side wall and the vault is approximately equal in single-track tunnels, while the damage degree of side wall is the largest, followed by the arch waist in double-track tunnels; when the in-situ stress is mainly horizontal, the most damaged parts are vault and invert.

The 2\# and 4\# diversion tunnels of Jinping II hydropower station are horseshoeshaped sections with a diameter of $13 \mathrm{~m}$. In reference [27], the location of stress-type failure that occurred in the complete or relatively complete surrounding rock of tunnel $2 \#$ and tunnel 4\# was recorded. In this process, special attention was paid to investigating actual geological conditions, to avoid counting the damage controlled by the structural plane. All the surrounding rocks of the tunnel in statistics are T2b marble.

The locations of 105 rockbursts that occurred in the 2\# and 4\# diversion tunnels with largely buried depths (1900-2400 m and 2160-2500 m) were statistically analyzed. Among 154 locations of 105 rockbursts, the proportion of each location is shown in Figure 14.

The super-buried depths are at 1900 2400 $\mathrm{m}$ and 2160 2500 m, and the in-situ stress in this section is mainly vertical stress. As can be seen from Figure 14, under this in-situ stress condition, the frequency of rockburst in different parts: side wall $>$ arch waist $>$ spandrel $>$ vault. The horseshoe tunnel used at the site is a double-track tunnel. When the in-situ stress is mainly vertical, rockburst occurs most frequently on the side wall and arch waist. 


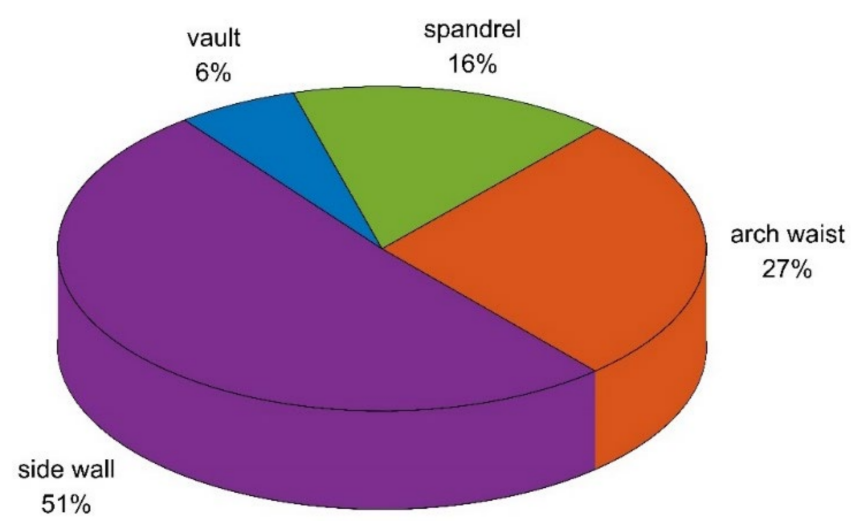

Figure 14. The proportion of each part of the rockburst.

\subsubsection{Suggestions for the Application of Action Location}

Table 8 summarizes the rockburst prone location under different section types based on the previous section's research.

Table 8. Summary of rockburst prone sites under different conditions.

\begin{tabular}{ccc}
\hline Section Type & In-Situ Stress & Prone Sites \\
\hline \multirow{2}{*}{ circular } & $\lambda=1$ & the whole ring \\
& $\lambda>1$ & vault and invert \\
arch waist \\
horseshoe & $\lambda<1$ & side wall and arch waist \\
& mainly vertical stress & single-track: side wall and vault \\
double-track: side wall
\end{tabular}

\section{The Rockburst Tunnel Calculation Model and Process}

\subsection{Calculation Model of Rockburst Tunnel}

The previous section gives the calculation method of impact load and the determination method of action location and range of impact load. After both are determined, the local load-structure model can be used for numerical calculation. Similar to the conventional load-structure model, the radial spring which can only be pressed, and the tangential spring which can be both be pulled and pressed are used to simulate the interaction between surrounding rock and supporting structure. The difference is the scope of action, which changes from the whole structure to the local structure. It should be noted that the action range of impact load may not be continuous and may be divided into two parts in some cases. It is also possible that rockburst may occur in the whole ring when the in-situ stress is too large, and at this time, the action range of impact load is the whole supporting structure.

The schematic diagram of the final local load-structure model is shown in Figure 15.

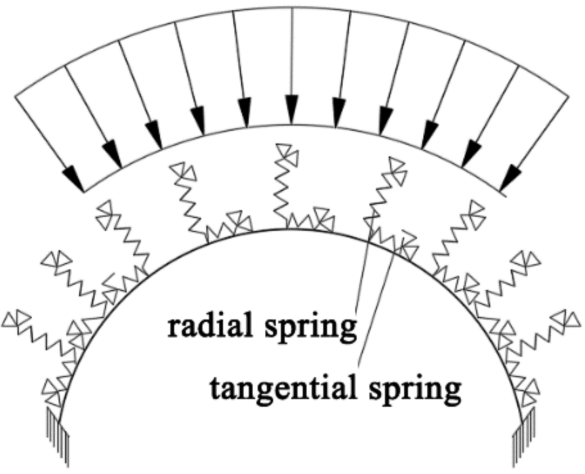

Figure 15. Schematic diagram of a local load-structure model of the rockburst tunnel. 


\subsection{Calculation Process of Rockburst Tunnel}

The load acting on the supporting structure is related to the size and velocity of the blasting block and the stiffness of the supporting structure. Even if the same size block acts on the supporting structure at the same speed, the supporting structure will bear different loads and deformation if the stiffness of the supporting structure is different. When the stiffness of the supporting structure is large, the deformation under the impact of blasting block is small and the impact load is large. When the stiffness of the supporting structure is small, its deformation under the impact of blasting block is large and the impact load is small. If a rockburst occurs without a supporting structure, in that case, even if the blasting block is ejected at a certain speed, there is no load acting on the supporting structure because the supporting structure does not exist.

Through the above analysis, it can be seen that the impact load acting on the supporting structure is not determined. In practical engineering, the type and parameters of supporting structure can be determined by analogy with similar engineering first, and then the impact load acting on supporting structure can be calculated accordingly. The local load-structure method is used to determine the supporting structure's safety factor and make a quantitative judgment of its safety. For the supporting structure where the safety factor does not meet the code's requirements or meets the requirements but has a small safety reserve, the supporting parameters can be adjusted. The above calculation can be carried out according to the adjusted supporting parameters until the safety needs of the project are met as shown in Figure 16.

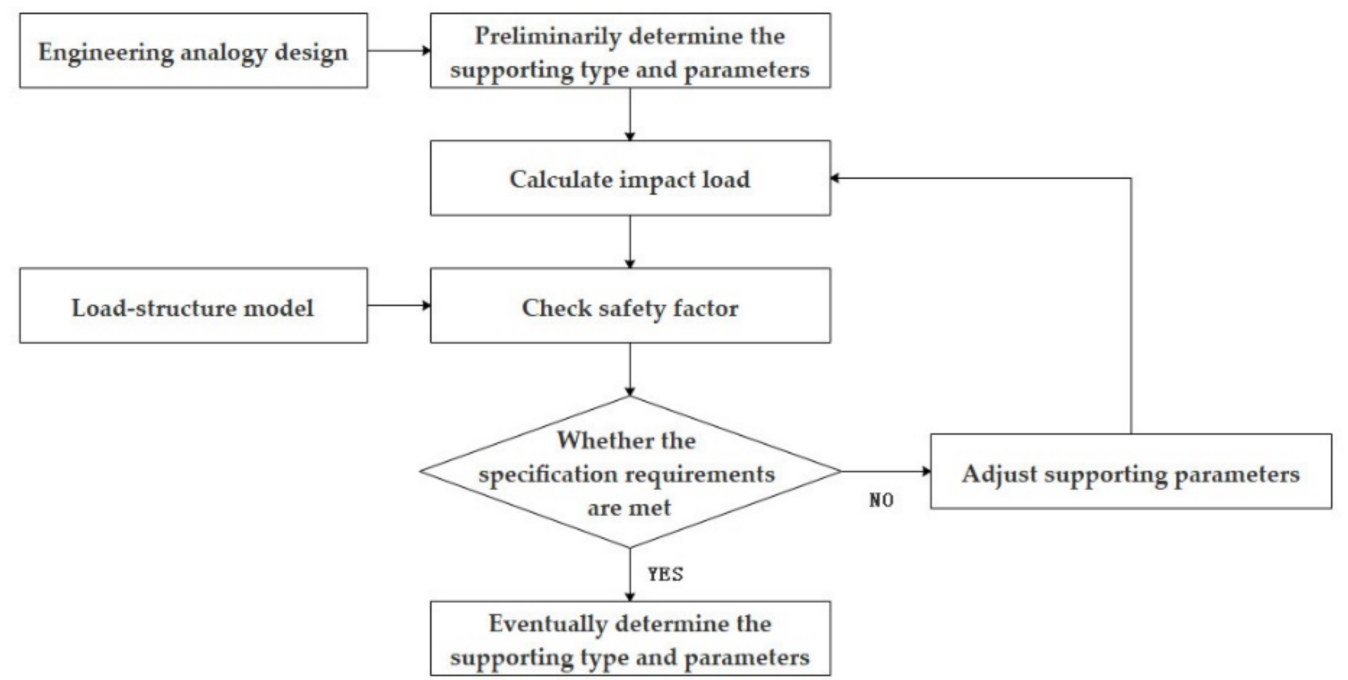

Figure 16. Design process.

\section{Example Analysis}

Assuming that the surrounding rock in the rockburst section is granite, the main surrounding rock parameters are selected as follows: elastic modulus $E=20 \mathrm{GPa}$, Poisson's ratio $\mu=0.25$, the in-situ stress is $40 \mathrm{MPa}$ and the lateral pressure coefficient is 1 , and the maximum strain energy density can be calculated as $150 \mathrm{~kJ} / \mathrm{m}^{3}$ according to Section 2.1 , the corresponding released kinetic energy is $76.5 \mathrm{~kJ} / \mathrm{m}^{3}$ according to Section 2.2 , and the corresponding supporting parameters are shown in Tables 9 and 10. 
Table 9. Supporting parameters of the rockburst section in single-track by drilling and blasting method.

\begin{tabular}{|c|c|c|c|}
\hline Rockburst Grade & Surrounding Rock Grade & Shotcrete $(\mathrm{cm})$ & Steel Frame \\
\hline \multirow[b]{2}{*}{ mild } & II & 5 & \\
\hline & III & 8 & \\
\hline \multirow{2}{*}{ medium } & II & 5 & \\
\hline & III & 8 & \\
\hline severe & II, III & Initial spraying: $5 \mathrm{~cm}$; Respraying: $15 \mathrm{~cm}$ & $\begin{array}{l}\text { Set in arch and wall, HW125 type, } \\
\text { Spacing } 1.2 \mathrm{~m}\end{array}$ \\
\hline extremely severe & II, III & Initial spraying: $5 \mathrm{~cm}$; Respraying: $18 \mathrm{~cm}$ & $\begin{array}{l}\text { Set in arch and wall, HW150 type, } \\
\text { Spacing } 1 \mathrm{~m}\end{array}$ \\
\hline
\end{tabular}

Table 10. Supporting parameters of the rockburst section in double-track by drilling and blasting method.

\begin{tabular}{cccc}
\hline Rockburst Grade & Surrounding Rock Grade & Shotcrete $\mathbf{( c m )}$ & Steel Frame \\
\hline \multirow{2}{*}{ Granite } & II & 5 & - \\
& III & 12 & - \\
medium & II & 5 & - \\
severe & III & 12 & Set in arch and wall, HW150 type, \\
& II, III & Initial spraying: $5 \mathrm{~cm} ;$ & Spacing $1.2 \mathrm{~m}$ \\
extremely severe & II, III & Respraying: $19 \mathrm{~cm}$ & Set in arch and wall, HW175 type, \\
& & Initial spraying: $5 \mathrm{~cm} ;$ & Spacing $1 \mathrm{~m}$ \\
\hline
\end{tabular}

\section{Calculation of Impact Load}

The location and range of rockburst were obtained by numerical simulation method, for the single-track and double-track types, and statistics were made for the results, as shown in Table 10. The results showed that rockburst might occur in the whole ring, but at different levels. However, according to the experience on-site, even if rockbursts repeatedly occur at the same section, they do not necessarily occur simultaneously, but often in order. When different grades of rockburst act separately, the impact on the structure is the most adverse. Therefore, when applying load, only one level of load shall be applied at a time. Taking extremely severe rockburst as an example, the load is applied to the vault with a range of $4.45 \mathrm{~m}$ in the single-line tunnel and the load is applied to the side wall with a range of $7.45 \mathrm{~m}$ in the double-track tunnel. Other levels of rockbursts refer to extremely severe rockbursts, which are used to determine the location and scope of impact load, as shown in Table 11.

Table 11. Parts and range of impact load.

\begin{tabular}{cccc}
\hline Section Type & Rockburst Grade & Acting Parts & Acting Range \\
\hline & mild & vault & $0.5 \mathrm{~m}$ \\
single-track & medium & vault & $1 \mathrm{~m}$ \\
& severe & vault & $3 \mathrm{~m}$ \\
& extremely severe & vault & $4.45 \mathrm{~m}$ \\
double-track & mild & side wall & $0.5 \mathrm{~m}$ \\
& medium & side wall & $1 \mathrm{~m}$ \\
& extremere & side wall & $3 \mathrm{~m}$ \\
\hline
\end{tabular}

The final kinetic energy release of surrounding rock per unit volume and the calculated velocity of blasting block are shown in Table 12 . 
Table 12. Calculation table of releasing kinetic energy and bursting block velocity of different levels of rockburst.

\begin{tabular}{|c|c|c|}
\hline Rockburst Grade & The Kinetic Energy Released Per Unit Volume of Surrounding Rock $\left(\mathrm{kJ} / \mathrm{m}^{3}\right)$ & The Velocity of Bursting Block $(\mathrm{m} / \mathrm{s})$ \\
\hline mild & 5 & 1.91 \\
\hline medium & 10 & 2.70 \\
\hline severe & 35 & 5.05 \\
\hline extremely severe & 76.5 & 7.46 \\
\hline
\end{tabular}

According to the determined supporting parameters and release kinetic energy, the impact loads under different rockburst grades are shown in Table 13.

Table 13. Impact load calculation table.

\begin{tabular}{ccc}
\hline Section Type & Rockburst Grade & Impact Load (kPa) \\
\hline & mild & 51.29 \\
single-track & medium & 103.80 \\
& severe & 443.18 \\
& extremely severe & 699.77 \\
double-track & mild & 36.50 \\
& medium & 135.70 \\
& severe & 414.57 \\
\hline
\end{tabular}

It can be seen from Table 13 that the impact loads of single-track tunnels and doubletrack tunnels are not the same. On the one hand, the shape and size of the two sections are different, which leads to the difference of supporting dimension coefficient $K_{0}$. On the other hand, the difference in thickness directly affects the flexural stiffness EI value of the supporting structure. However, in terms of results, there was not much difference overall.

\section{Safety Factor Checking}

The factor of safety is checked by ANSYS numerical simulation software, and the calculation model by the local load-structure model. The established structure model of the single-track tunnel is shown in Figure 17.

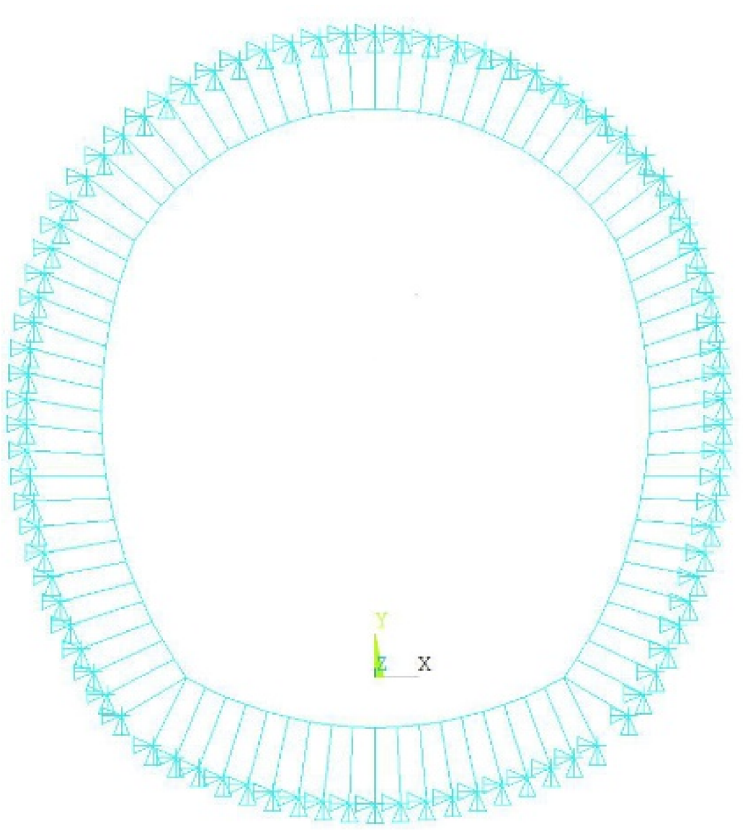

Figure 17. Schematic diagram of the geometric model. 
Taking the single-track tunnel as an example, the supporting structure's bending moment and axial diagram are calculated, as shown in Figures 18 and 19.

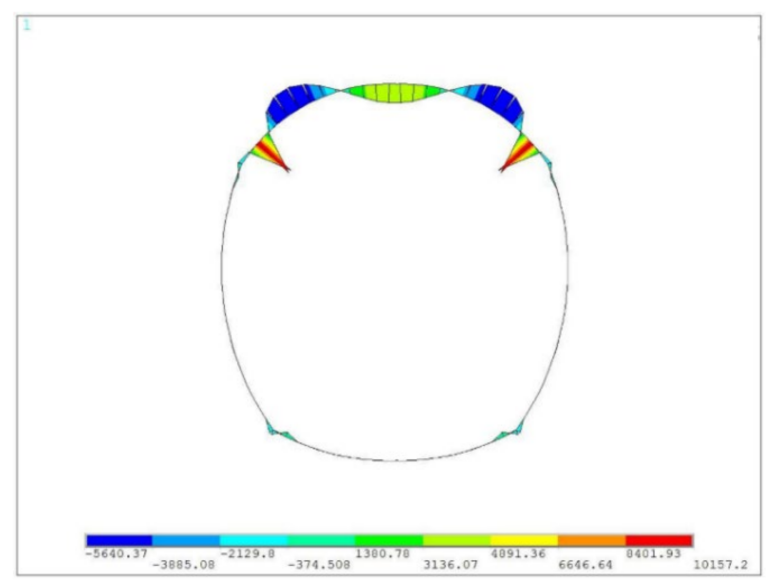

Figure 18. Bending moment diagram of supporting structure.

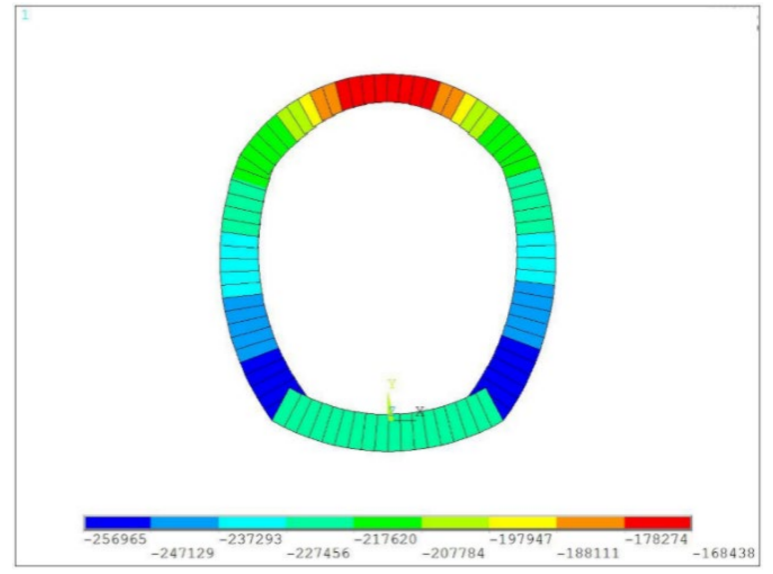

Figure 19. Axial diagram of supporting structure.

The final calculation results of the rockburst safety factor are summarized in Table 14

Table 14. Safety factor check table of rockburst tunnel.

\begin{tabular}{|c|c|c|c|c|c|}
\hline Section Type & Rockburst Grade & $\begin{array}{c}\text { Minimum Safety } \\
\text { Factor }\end{array}$ & Pull or Press & Part & Control Standards \\
\hline \multirow{4}{*}{ single-track } & mild & 3.24 & pull & vault & 2.7 (pull) \\
\hline & medium & 2.88 & pull & vault & 2.7 (pull) \\
\hline & severe & 1.83 & pull & vault & 1.8 (pull) \\
\hline & extremely severe & 1.35 & pull & vault & 1.8 (pull) \\
\hline \multirow{4}{*}{ double-track } & mild & 3.95 & press & side wall & 1.8 (press) \\
\hline & medium & 2.94 & press & side wall & 1.8 (press) \\
\hline & severe & 2.12 & pull & side wall & 1.8 (pull) \\
\hline & extremely severe & 1.47 & pull & side wall & 1.8 (pull) \\
\hline
\end{tabular}

According to the calculation results in Table 14, except for extremely severe rockburst, rockburst of other levels can meet the requirements of minimum factor safety, but the safety reserve is small. In practical engineering, parameters can be adjusted in real-time according to relevant calculation results to ensure the safety of the supporting structure. The safety of the supporting structure can be improved by adopting other auxiliary construction measures, such as stress release holes and high-pressure water injection. 


\section{Conclusions}

From the perspective of energy with the method of structural mechanics, this paper deduces the calculation method of impact load of rockburst tunnel acting on the supporting structure, determines the action location of impact load under different section types and different section sizes, and derives the local load-structure calculation model and the calculation process designed by this model. The main conclusions are as follows:

(1) Using the method of structural mechanics, the calculation method of impact load of rockburst tunnel acting on the supporting structure is deduced. The expression form of impact load is uniform load. The dynamic load factor $K$ in the formula is related to the stiffness $E I$ of the supporting structure and the supporting dimension coefficient $K_{0}$. The support dimension coefficient $K_{0}$ is related to the size and type of support section, which reflects the difference in load-deformation relations between tunnel sections.

(2) Rockburst-prone parts of circular tunnel are related to lateral pressure coefficient: when $\lambda=1$, the probability of rockburst occurring in the whole ring is the same; when $\lambda>1$, the vault and inverted roof are most prone to rockburst; when $\lambda<1$, the arch waist is most prone to rockburst. In the horseshoe tunnel, when the vertical stress is dominant, the parts prone to rockburst are the side walls on both sides and the arch waist. When the vertical and horizontal stresses are equivalent, the rockburst-prone parts of the single-track tunnel are side wall and vault. The double-track tunnel is a side wall; when the horizontal stress is dominant, the prone parts to rockburst are vault and invert.

(3) Finally, the local load-structure model based on the impact load calculation method can be used for quantitative estimation of the rockburst tunnel. The type and parameters can be determined by analogy with similar projects during calculation. After calculating the impact load, the parameters of the supporting structure whose factor of safety does not meet the requirements can be adjusted until the project's safety requirements are met.

Author Contributions: Conceptualization, Z.Y. and H.T.; Methodology, Z.Y.; Software, Z.Y. and D.Z.; Validation, Z.Y., D.L., Z.W., D.Z. and H.T.; Formal analysis, Z.Y., D.L. and D.Z.; Investigation, D.L. and H.T.; Resources, Z.W. and H.T.; Data curation, D.Z.; Writing-original draft preparation, Z.Y.; Writing-review and editing, D.L.; Visualization, Z.Y. and D.Z.; Supervision and project administration: Z.Y. and D.L. All authors have read and agreed to the published version of the manuscript.

Funding: This research was funded by Science and technology research and development project of China National Railway Group (P2019G038-5).

Data Availability Statement: The data presented in this study are available on request from the corresponding author.

Acknowledgments: We acknowledge SWJTU (Southwest Jiaotong University) and the staff for their technical support and assistance.

Conflicts of Interest: The authors declare no conflict of interest.

\section{References}

1. Cheng, L.; Jianfeng, L.; Yi, R.; Chao, L.; Yilin, L. Study on Very Long-Term Creep Tests and Nonlinear Creep-Damage Constitutive Model of Salt Rock. Int. J. Rock Mech. Min. Sci. 2021, 146-156.

2. Lyu, C.; Liu, J.; Ren, Y.; Liang, C.; Zhang, Q. Study on Long-Term Uniaxial Compression Creep Mechanical Behavior of Rocksalt-Mudstone Combined Body. Int. J. Damage Mech. 2021, 1-19. [CrossRef]

3. Xie, H.; Pei, J.; Zuo, J.; Zhang, R. Investigation of Mechanical Properties of Fractured Marbles by Uniaxial Compression Tests. J. Rock Mech. Geotech. Eng. 2011, 3, 302-313. [CrossRef]

4. Zhou, H.; Chen, S.; Li, H.; Liu, T.; Wang, H. Rockburst Prediction for Hard Rock and Deep-Lying Long Tunnels Based on the Entropy Weight Ideal Point Method and Geostress Field Inversion: A Case Study of the Sangzhuling Tunnel. Bull. Eng. Geol. Environ. 2021, 80, 3885-3902. [CrossRef] 
5. Gong, Q.M.; Yin, L.J.; Wu, S.Y.; Zhao, J.; Ting, Y. Rock Burst and Slabbing Failure and Its Influence on Tbm Excavation at Headrace Tunnels in JINPING II Hydropower Station. Eng. Geol. 2012, 124, 98-108. [CrossRef]

6. Naji, A.M.; Emad, M.Z.; Rehman, H.; Yoo, H. Geological and Geomechanical Heterogeneity in Deep Hydropower Tunnels: A Rock Burst Failure Case Study. Tunn. Undergr. Sp. Technol. 2019, 84, 507-521. [CrossRef]

7. Xue, R.; Liang, Z.; Xu, N.; Dong, L. Rockburst Prediction and Stability Analysis of the Access Tunnel in the Main Powerhouse of a Hydropower Station Based on Microseismic Monitoring. Int. J. Rock Mech. Min. Sci. 2020, 126, 1365-1609. [CrossRef]

8. He, S.; Lai, J.; Zhong, Y.; Wang, K.; Xu, W.; Wang, L.; Liu, T.; Zhang, C. Damage Behaviors, Prediction Methods and Prevention Methods of Rockburst in 13 Deep Traffic Tunnels in China. Eng. Fail. Anal. 2021, 121, 105178. [CrossRef]

9. Zhou, Y.; Zhao, D.; Li, B.; Wang, H.; Zhang, Z. Fatigue Damage Mechanism and Deformation Behaviour of Granite under Ultrahigh-Frequency Cyclic Loading Conditions. Rock Mech. Rock Eng. 2021, 54, 4723-4739. [CrossRef]

10. Han, Z.; Li, D.; Zhou, T.; Zhu, Q.; Ranjith, P.G. Experimental Study of Stress Wave Propagation and Energy Characteristics across Rock Specimens Containing Cemented Mortar Joint with Various Thicknesses. Int. J. Rock Mech. Min. Sci. 2020, $131,104352$. [CrossRef]

11. Li, D.; Han, Z.; Sun, X.; Zhou, T.; Li, X. Dynamic Mechanical Properties and Fracturing Behavior of Marble Specimens Containing Single and Double Flaws in SHPB Tests. Rock Mech. Rock Eng. 2019, 52, 1623-1643. [CrossRef]

12. Müller, W. Numerical Simulation of Rock Bursts. Min. Sci. Technol. 1991, 12, 27-42. [CrossRef]

13. Cook, N.; Hoek, E.P.; Pretorius, J.; Ortlepp, W.D.; Salamon, M. Rock Mechanics Applied to the Study of Rockbursts. J. S. Afr. Inst. Min. Metall. 1966, 66, 435-528.

14. Wang, J.; Zuo, T.; Li, X.; Tao, Z.; Ma, J. Study on the Fractal Characteristics of the Pomegranate Biotite Schist under Impact Loading. Geofluids 2021, 2021, 1570160. [CrossRef]

15. Ma, J.; Li, X.; Wang, J.; Tao, Z.; Zuo, T.; Li, Q.; Zhang, X. Experimental Study on Vibration Reduction Technology of Hole-by-Hole Presplitting Blasting. Geofluids 2021, 2021, 5403969. [CrossRef]

16. Fang, Q.; Wang, G.; Yu, F.; Du, J. Analytical Algorithm for Longitudinal Deformation Profile of a Deep Tunnel. J. Rock Mech. Geotech. Eng. 2021, 13, 845-854. [CrossRef]

17. Mingqing, X.; Shaofeng, W.; Libao, C. Research on the Design Method of Primary Support of Tunnel Based on the Load-Structure Method. J. Railw. Eng. Soc. 2018, 35, 60.

18. Li, T.; Meng, L.; Wang, L. Stability of High-Stress Tunnels and Prevention of Rockburst and Large Deformation Disasters; Science Press: Beijing, China, 2016.

19. Cai, M.; Kaiser, P. Assessment of Excavation Damaged Zone Using a Micromechanics Model. Tunn. Undergr. Sp. Technol. 2005, 20, 301-310. [CrossRef]

20. Gao, Y.; Zhang, H.; Zhao, G.; Cheng, X. Study on Rockburst Mechanism and Prevention Practice of Deep Buried Long Tunnel; China Water \& Power Press: Beijing, China, 2014.

21. Zuo, Y.J.; Li, X.B.; Zhou, Z.L. Determination of Ejection Velocity of Rock Fragments during Rock Burst in Consideration of Damage. J. Cent. South Univ. Technol. 2005, 12, 618. [CrossRef]

22. Mcgarr, A. A Mechanism for High Wall-Rock Velocities in Rockbursts. Pure Appl. Geophys. 1997, 150, 381-391. [CrossRef]

23. Linkov, A.M. Rockbursts and the Instability of Rock Masses. Int. J. Rock Mech. Min. Sci. GeoMech. Abstr. 1996, 33, 727-732. [CrossRef]

24. Ortlepp, W. High Ground Displacement Velocities Associated with Rockburst Damage. Rockbursts Seism. Min. 1993, 93, 101-106.

25. Hoek, E.; Brown, E.T. Practical Estimates of Rock Mass Strength. Int. J. Rock Mech. Min. Sci. 1997, 34, 1165-1186. [CrossRef]

26. Liu, L.; Ling, Y.; Li, N.; Pang, T. Research and Case Analysis of Rock Burst Disaster in Deep Hydraulic Tunnel; China Water \& Power Press: Beijing, China, 2019.

27. Yamashi, F.; Zhang, C.; Shao-Jun, L.; Qiu, S.-L.; Zhang, C. Dynamic Design Method for Deep Tunnels in Hard Rock; Science Press: Beijing, China, 2013. 